\title{
Direct and indirect methods for the quantification of leg volume: comparison between water displacement volumetry, the disk model method and the frustum sign model method, using the correlation coefficient and the limits of agreement
}

\author{
D.M.K.S. Kaulesar Sukul, P.T. den Hoed, E.J. Johannes, R. van Dolder* and \\ E. Benda*
}

Department of General Surgery/Traumatology and *Department of Physiotherapy, University Hospital Rotterdam 'Dijkzigt', The Netherlands

Received September 1992, accepted May 1993

\begin{abstract}
Volume changes can be measured either directly by water-displacement volumetry or by various indirect methods in which calculation of the volume is based on circumference measurements. The aim of the present study was to determine the most appropriate indirect method for lower leg volume calculation using water displacement volumetry as a 'golden standard'. For 20 male valunteers, age range: 20-3.5 years, the volume of both lower legs was determined directly by water-displacement volumetry, and indirectly by the frustum sign model method and the disc model method. Calculation of the correlation coefficient and the limits of agreement showed that water-displacement volumetry and the disc model method are interchangeable $(\mathrm{r}=+0.99$, mean $\pm 2 s=-45 \pm 78 \mathrm{ml})$, whereas this does not hold for the frustum sign model $(\mathrm{r}=+0.93$, mean $\pm 2 s=521 \pm 238 \mathrm{ml})$. In the clinical situation volume measurement can be valuable for monitoring of the severity of oedema or haematoma occurrence after surgery or severe trauma. This non-invasive diagnostic aid may be a valuable adjuvant means of diagnosis for several volume dependent disorders of the extremities.
\end{abstract}

Keywords: Volume measurements, water-displacement volumetry, disc model, frustum sign model, limits of agreement

\section{INTRODUCTION}

Calculation of the volume of an extremity has not yet been adopted for daily routine practice because neither the technique nor the clinical relevance is known. Volume changes can be measured either directly by water-displacement volumetry or one of various indirect methods where calculation of the volume is based on circumference measurements. Water-displacement volumetry has been found to be a sensitive method ${ }^{1}$, although it is time-consuming and not suitable for patients in the immediate postoperative period. For these reasons a study was performed to find an indirect method for calculation of the leg volume; a method which has great validity, is rapid, and can be used in any clinical situation.

Several indirect methods have been described for the calculation of leg volume ${ }^{2-4}$. The simplest of these methods is application of the formula for a truncated cone (frustum sign) for which only the lower and the upper circumferences of the lower leg have to be

Correspondence and reprint requests to: D.M.K.S. Kaulesar Sukul, MD, PhD, University Hospital Rotterdam Dijkzigt, Department of General Surgery/Traumatology, Dr. Molewaterplein 40, 3015 GD Rotterdam, The Netherlands

(C) 1993 Butterworth-Heinemann for BES

$0141-5125 / 93 / 061.77-04$ measured $^{4}$. This formula is:

$$
V=\frac{\pi}{3} h\left(R^{2}+R r+r^{2}\right)
$$

A swollen extremity can be visualized as a cone that is reduced to its 'frustum' for volume calculations. A simple, right-angle cone is diagrammed into its frustum with component radius and height measurements for calculation of the frustum. The radius can be calculated from the circumference and the height is the distance between two circumferences.

Another method for the calculation of leg volume is to divide the leg into discs with a height of $3 \mathrm{~cm}$, this is called the disc model. The total volume is equal to the sum of the individual disc volumes ${ }^{3}$ as follows:

$$
V=\sum_{i=1}^{n}\left(\frac{C_{\mathrm{i}}^{2}}{4 \pi} \times h\right)
$$

Kuhnke (1976) described a corrected disc model in which the total volume of the lower leg has to be decreased by half the volume of the first and the last discs $^{3}$. This author recommended the normal disc model for calculation of the lower leg volume, because the difference between the volume of the 
corrected disc model and that of the normal disc model is not significant.

A study performed to compare the waterdisplacement volumetry, the disc model method and the frustum sign model method has not yet been reported in the literature.

The aim of the present study was to assess the reliability of the disc model method and the frustum sign model method for calculation of the volume of the lower leg as compared with water-displacement volumetry and which of these methods is most appropriate for measurement of volume changes of the lower leg in clinical situations.

\section{PATIENTS AND METHODS}

For 20 healthy male amateur soccer players with an age range of 20-35 years, the volume of both lower legs $(n=40)$ was measured. The reference points marked on the lower leg were chosen by dividing the lower leg into horizontal discs with a height of $3 \mathrm{~cm}$, starting $3 \mathrm{~cm}$ below the medial gap of the knee joint surface. The last disc was the one just above the medial malleolus.

The lower legs of all these subjects were measured according to the following methods:
(a) water-displacement volumetry,
(b) the disc model method,
(c) the frustum sign model method.

\section{Water-displacement volumetry}

For water-displacement volumetry use was made of a special tank provided with two overflow tubes. Before each measurement, the tank was filled with warm water $\left(29^{\circ} \mathrm{C}\right)$ up to the lower overflow tube. The difference between the lower and the upper overflow tubes was $3020 \mathrm{ml}$, the so-called reserve volume. A temperature of $29^{\circ} \mathrm{C}$ was chosen because the skin temperature of the leg and the ankle region approximates that value ${ }^{5}$. The lower overflow tube was closed. Two graduated cylinders with a capacity of 1 litre and an accuracy of $10 \mathrm{ml}$ were placed under the upper overflow tube. The patient then lowered one leg carefully and slowly into the tank until the water level reached the upper reference point. The volume of spillwater was measured when the dripping had almost stopped (less than one drop per sec). The volume of the lower extremity (leg, ankle, and foot) is $3020 \mathrm{ml}$, the reserve volume, plus the amount of water in the cylinder. Next the tank was filled again as far as the upper overflow tube. The ankle and foot were immersed in the water until the water level reached the lower reference point. The amount of water in the cylinders is the volume of ankle and foot. The leg volume is the volume of the lower extremity minus the volume of ankle and foot.

\section{Accuracy of measurement}

It was necessary to know the accuracy of the measurement of the water-displacement volumetry because this was used as a 'golden standard' for the validity of the indirect volume measurements. To calibrate the water tank, we placed an object with a standard volume of $1240 \mathrm{ml}$ in the tank and collected and measured the spillwater. These measurements were repeated 10 times.

\section{Disc model method}

An indirect method for calculation of the leg volume is to divide the leg into discs. Each disc is $3 \mathrm{~cm}$ high. The total volume of the leg is equal to the sum of the individual disc volumes:

$$
\begin{aligned}
& C=2 \pi \times r \\
& S=\pi \times r^{2}
\end{aligned}
$$

Disc volume $=\pi \times\left(C^{2} / 4 \pi^{2}\right) \times h$

$$
V=\sum_{\mathrm{i}=1}^{n}\left(\left(C_{\mathrm{i}}^{2} / 4 \pi\right) \times \mathrm{h}\right)
$$

$V$ is the total volume of the leg, $C$ is the circumference of the disc, $S$ is the cross-section surface of the disc, $r$ is the radius of the disc, $i$ is the number of discs and $h$ is the height of the disc $(h=3 \mathrm{~cm})$.

\section{Frustum sign model method}

The leg volume was quantified by calculation according to the formula describing the volume of a truncated cone or frustum:

$$
\begin{aligned}
& V=\frac{\pi}{3} \times h\left(R^{2}+R r+r^{2}\right) \\
& R=\frac{C}{2 \pi}, \quad r=\frac{c}{2 \pi}
\end{aligned}
$$

or, if we proceeded from the circumference:

$$
\begin{aligned}
& V=\frac{\pi}{3} \times h\left(\left(\frac{C}{2 \pi}\right)^{2}+\frac{C}{2 \pi} \cdot \frac{c}{2 \pi}+\left(\frac{c}{2 \pi}\right)^{2}\right) \\
& V=\frac{\pi}{12 \pi^{2}} \times h\left(C^{2}+C c+c^{2}\right)
\end{aligned}
$$

$V$ is the volume of the lower leg, $R$ is the radius of the uppermost disc of the lower leg, $C$ is the circumference of the uppermost disc of the lower leg, $r$ is the radius of the lowermost disc of the lower leg, $c$ is the circumference of the lowermost disc of the lower leg and $h$ is the calculated distance between the uppermost and the lowermost discs. The circumferences were measured with a measuring-tape with an accuracy of $1 \mathrm{~mm}$.

Statistical analysis of the data was performed. Data were analysed by linear regression using computer software (BMDP - Package) in the least-square fitting mode. Pearson's correlation coefficient was used to evaluate the relationship between the results of waterdisplacement volumetry and the disc model method and the relationship between water-displacement volumetry and the frustum sign model method.

The limits of agreement are an approach for measuring agreement, based on graphic techniques, according to Bland $e t a l^{6}$, and were used to determine whether the results obtained with these methods indeed agree. 


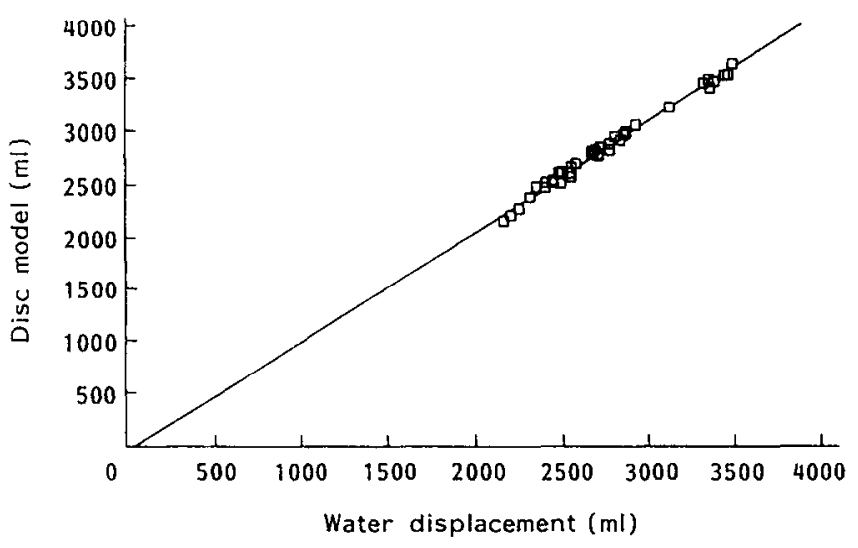

Figure 1 Linear regression of the disc model method as a function of water-displacement volumetry. The line is represented by $y=$ $32.13+1.030 x$, where $y$ is the leg volume calculated from circumference measurements and $x$ the measurement based on water displacement. Correlation coefficient $r=+0.99$

\section{RESULTS}

\section{Accuracy of measurement}

When the volume of a fixed object was determined by water-displacement volumetry, the greatest difference between measurements was $10 \mathrm{ml}$. The mean volume was $1245 \mathrm{ml}(1240-1250 \mathrm{ml})$, the standard deviation $4.7 \mathrm{ml}$.

The relationship between water-diplacement volumetry and the disc model method is shown in Figure 1 . The values fit with a correlation coefficient of +0.99 to a straight line with the formula $y=$ $-32.13+1.030 x$, where $y$ is the leg volume calculated from circumference measurements and $x$ the measurement based on water displacement. The mean volume yielded by water-displacement volumetry was $2771 \mathrm{ml}$ (range: $2180-3510 \mathrm{ml}$ ), and the mean volume obtained with the disc model method was $2822 \mathrm{ml}$ (range: $2146-3619 \mathrm{ml}$ ). The mean difference $(\bar{d})$, water-displacement minus disc model, is $-45 \mathrm{ml}$ with a standard deviation $(s)$ of $39 \mathrm{ml}$. The socalled limits of agreement of the water-displacement volumetry versus the disc model method are:

$$
\begin{aligned}
& \bar{d}-2 s=-45-(2 \times 39)=-123 \mathrm{ml} \\
& \bar{d}+2 s=-45+(2 \times 39)=+33 \mathrm{ml}(\text { Figure } 2)
\end{aligned}
$$

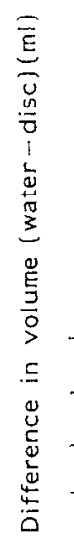

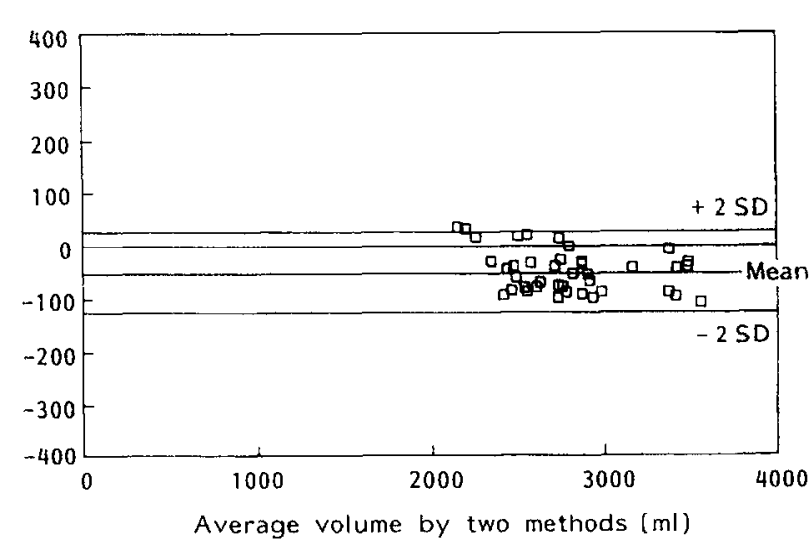

Figure 2 Limits of agreement of the water-displacement volumetry and the disc model method. Mean $-2 \mathrm{~s}--123 \mathrm{ml}$, mean $+2 s=$ $+33 \mathrm{ml}$

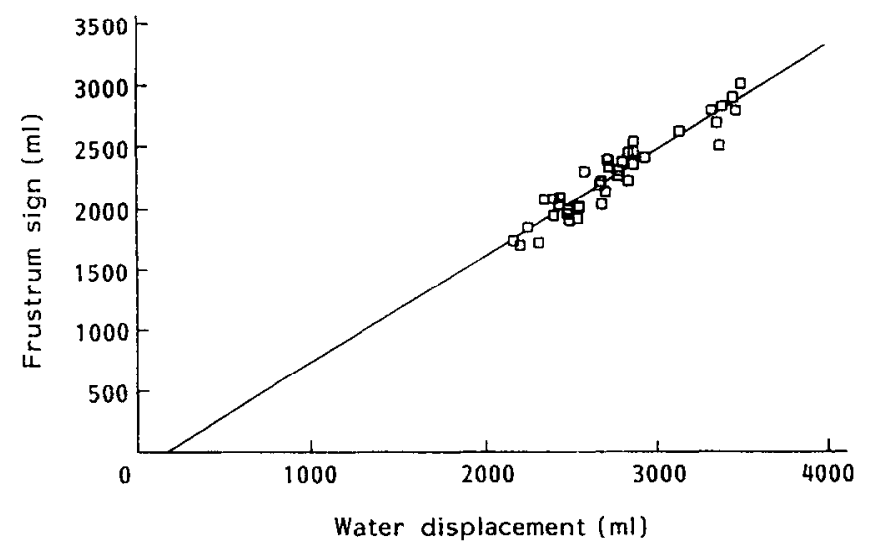

Figure 3 Linear regression of the frustum sign model method as a function of water-displacement volumetry. The line is represented by $y=-201.6+0.862 x$, where $y$ is the leg volume calculated from circumference measurements and $x$ the measurement based on water displacement. Correlation coefficient $r=+0.93$

The standard error of $\bar{d}$ is $6.2 \mathrm{ml}$. For the $95 \%$ confidence interval, there are 39 degrees of freedom and $t=2.02$. The $95 \%$ confidence interval for the bias is -57.5 to $-32.5 \mathrm{ml}$. The standard error of the limit $\bar{d}-2 s$ is $10.7 \mathrm{ml}$. The $95 \%$ confidence interval for the lower limit of agreement is -144.6 to $-101.4 \mathrm{ml}$ and for the upper limit of agreement 11.4 to $54.6 \mathrm{ml}$. Thus, the disc model method tended to give a larger volume of $45 \mathrm{ml}$ with a $95 \%$ confidence interval of $32.5 \mathrm{ml}$ and $57.5 \mathrm{ml}$.

The relationship between the water-displacement volumetry and the frustum sign model method is shown in Figure 3. The values fit with a correlation coefficient of +0.93 to a straight line with the formula $y=-201.6+0.862 x$, where $y$ is the leg volume calculated from circumference measurements and $x$ the measurement based on the water displacement. The mean volume obtained with the frustum sign method was $2187 \mathrm{ml}$ (range: $1702-2996 \mathrm{ml}$ ). The mean difference $(\bar{d})$, i.e. water-displacement minus frustum sign, is $521 \mathrm{ml}$ with a standard deviation $(s)$ of $119 \mathrm{ml}$. The limits of agreement of the water-displacement volumetry versus the frustum sign model method are:

$$
\begin{aligned}
& \bar{d}-2 s=521-(2 \times 119)=283 \mathrm{ml} \\
& \bar{d}+2 s=521+(2 \times 119)=759 \mathrm{ml} \text { (Figure } 4)
\end{aligned}
$$

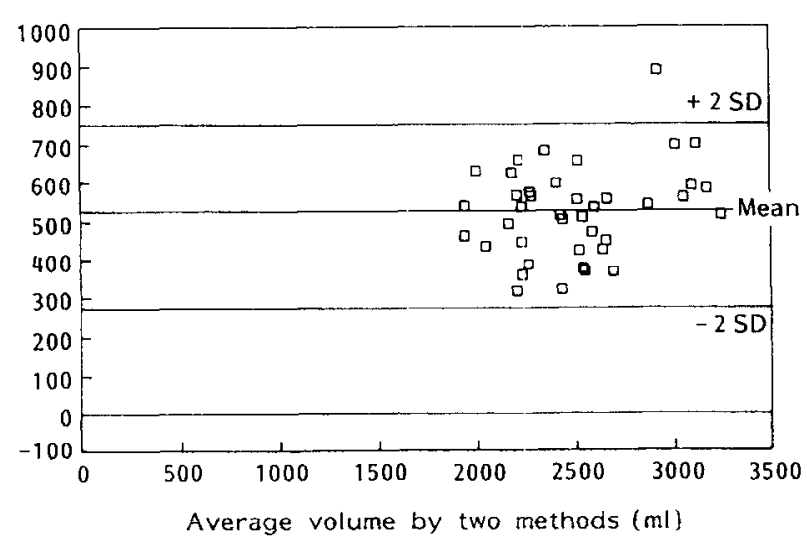

Figure 4 Limits of agreement of the water-displacement volumetry and the frustum sign model method. Mean $-2 \mathrm{~s}=283 \mathrm{ml}$, mean + $2 s=759 \mathrm{ml}$ 
The standard error of $\bar{d}$ is $10.7 \mathrm{ml}$. The $95 \%$ confidence interval for the bias is 483 to $559 \mathrm{ml}$. The standard error of the limit $\bar{d}-2 s$ is $32.6 \mathrm{ml}$. The $95 \%$ confidence interval for the lower limit of agreement is 217.2 to $348.8 \mathrm{ml}$ and for the upper limit of agreement 693.2 to $824.8 \mathrm{ml}$.

\section{DISCUSSION}

The advantage of water-displacement volumetry is the possibility of direct measurement of objects with an irregular form. This method has problems of hygiene, is very time-consuming (two successive measurements take about $20-30 \mathrm{~min}$ ), and is not suitable for measurement of the volumes of extremities of patients in the immediate postoperative period. When water-displacement volumetry is properly performed, the systemic failure will be small. The methodological failure is however, difficult to determine, and correction after lowering of the leg beyond the reference point is not possible.

In 1981, Stranden ${ }^{5}$ compared the frustum sign model with water-displacement volumetry. In that study nine patients, with unilateral leg oedema following femoropopliteal bypass grafting, were examined and a correlation coefficient of +0.98 was found ${ }^{5}$. We disagree with the author's conclusion that for quantification of leg oedema, the frustum sign model method is satisfactory for clinical purposes. The use of a correlation coefficient can be misleading; a higk correlation coefficient does not always mean that two methods indeed agree 6 . For that reason, we calculated not only the correlation coefficient but also the limits of agreement in our study.

Comparison of water-displacement volumetry and the frustum sign model method has shown that even with the most optimistic interpretation, based on the high correlation coefficient $(r=+0.93)$, there can be considerable discrepancy between the two methods because there is an unacceptable degree of agreement, reflecting the great variation of differences. Comparison of the water-displacement volumetry and the disc model method shows a very high correlation coefficient $(r=+0.99)$, and clinically an acceptable agreement. The disc model method tends to give a larger volume ( $45 \mathrm{ml})$ with a $95 \%$ confidence interval of $32.5 \mathrm{ml}$ and $57.5 \mathrm{ml}$. The limits of agreement are small enough to clinically justify that these two methods can be used interchangeably.

From the present results it may be concluded that water-displacement volumetry and the disc model method are interchangeable and that waterdisplacement volumetry cannot be replaced by the frustum sign model method.

In the clinical situation, volume measurements can be valuable for monitoring the severity of the oedema or haematoma after surgery or trauma. Lennihan ${ }^{4}$ and Clarke $e t a l{ }^{7}$ described a number of patients with a great volume difference between the left and right legs after vascular surgery. For determination of leg volume changes it is necessary repeatedly to determine the entire volume of the lower leg.

Volumetry in combination with the clinical signs and if necessary measurement of the intracompartmental pressure is likely to give us all information for diagnosing an impending compartment syndrome in an early stage.

Volumetry is a non-invasive diagnostic aid, which may be a valuable adjuvant means of diagnosis for several volume dependent disorders of the extremities.

\section{ACKNOWLEDGEMENTS}

The overflow tank was made by the Institute of Central Research, University Hospital Rotterdam Dijkzigt. The statistics were performed by the Institute of Epidemiology and Biostatistics, Erasmus University Rotterdam. Their assistance and cooperation are gratefully appreciated.

\section{REFERENCES}

1. Nilsson S, Bjerkness Haugen G. Volumetry in the evaluation of swelling in ankle and foot. J Oslo City Hosp 1981; 31: $11-15$

2. Katch V, Michael ED, Amuchie FA. The use of bodyweight and girth measurement in predicting segmental leg volumes of females. Hum Biol 1973; 45: 293-303.

3. Kuhnke E. Volumbestimmung aus Umfangmessungen. Folia Angiologica 1976; 24: 228-32.

4. Lennihan $R$, Mackereth $M$. Calculating volume changes in a swollen extremity from surface measurements. Am J Surg 1973; 126: 649-52.

5. Stranden E. A comparison between surface measurements and water displacement volumetry for the quantification of leg oedema. J Oslo City Hosp 1981; 31: 153-55.

6. Bland JM, Altman DG. Statistical methods for assessing agreement between two methods of clinical measurement. Lancet 1986; 8: 307-10.

7. Clarke R, Topley E, Flear CTG. Assessment of blood-loss in civilian trauma. Lancet 19.55; 1: 629 